\title{
Prediction and Prevention of Postpolypectomy Bleeding: Current Challenging Issues
}

\author{
Duck-Woo Kim \\ Department of Surgery, Seoul National University Bundang Hospital, Seongnam, Korea
}

\section{See Article on Page 182-185}

The colonoscopic polypectomy is at the forefront in reducing the incidence of colorectal cancer. However, the endoscopic polypectomy has been reported to be accompanied by risks of complications. Postpolypectomy bleeding (PPB) is the most common complication, with an incidence ranging from $0.6 \%$ to $8 \%$ in large series [1-3]. The incidence of PPB has been reported to depend on its definition: early, delayed, and overall [4].

Many factors are associated with an increased risk for PPB and can be categorized into patient-, polyp-, and procedure-related factors. Patient-related factors include the use of an anticoagulant agent and various host comorbidities such as hypertension, severe pulmonary disease, and chronic renal failure. Recently, as more individuals are taking anticoagulant or antiplatelet agents such as warfarin, clopidogrel, aspirin, and nonsteroidal anti-inflammatory drugs, preventing PPB in these patients has become one of challenging issues in a colonoscopic polypectomy. A large retrospective cohort study reported warfarin therapy to be an independent predictor of PPB (adjusted odds ratio, 11.6; 95\% confidence interval, 2.3-57.3) and suggested that additional methods to reduce the likelihood of PPB in anticoagulated patients should be investigated [5]. However, warfarin interruption for a colonoscopy also has an increased risk of a thromboembolic event. Garcia et al. [6] reported thromboembolic events in $0.7 \%$ of 1,293 patients with warfarin interruptions, and Blacker et al. [7] reported that strokes occurred in $1 \%$ of 987 patients with atrial fibrillation after temporary anticoagulation discontinuation. Until now,

Correspondence to: Duck-Woo Kim, M.D.

Department of Surgery, Seoul National University Bundang Hospital, 82 Gumi-ro 173beon-gil, Bundang-gu, Seongnam 463-707, Korea

Tel: +82-31-787-7101, Fax: +82-31-787-4078

E-mail:kdw@snubh.org

(c) 2014 The Korean Society of Coloproctology

This is an open-access article distributed under the terms of the Creative Commons Attribution NonCommercial License (http://creativecommons.org/licenses/by-nc/3.0) which permits unrestricted noncommercial use, distribution, and reproduction in any medium, provided the original work is properly cited. whether antiplatelet agents such as aspirin increase the risk of PPB has been debatable [4]. Among polyp-related factors associated with PPB, the size of the polyp, as Moon et al. [8] showed in his retrospective study of the current issue, seems to have the most data supporting it. Polyps larger than $10 \mathrm{~mm}$ have been reported to have a 2- to 4.5-times increased risk of PPB $[3,9]$.

Several colonoscopic procedures, such as injection of an epinephrine solution, endoloops, hemoclips, and argon plasma coagulation, have been proposed for the prevention of PPB. A few randomized studies comparing these methods have been reported [10-14]. Each method has its own efficacy and its own advantages in reducing the risk of PPB; however, none of these methods is totally superior to the others. Kapetanos et al. [4] summarized the key points from these randomized studies as follows: (1) The injection of saline-epinephrine solution at the base of the polyp can prevent early, but not delayed, bleeding. (2) Loop placement can prevent bleeding but, especially in large $(>2 \mathrm{~cm})$ polyps, this effect is restricted to early bleeding. (3) Clips may also prevent hemorrhage, but this has not been proven in a randomized trial. (4) Combination techniques may be more effective than a single technique.

Although the overall incidence of PPB is rare, neglecting a meticulous precolonoscopy evaluation of patients to predict the risk factors of PPB and decrease the frequency of this complication cannot be justified. Appropriate use of various methods of PPB prophylaxis can help in reducing the risk of $\mathrm{PPB}$, but more controlled data seem to be needed to clarify the roles of these methods.

\section{REFERENCES}

1. Singh H, Penfold RB, DeCoster C, Kaita L, Proulx C, Taylor G, et al. Colonoscopy and its complications across a Canadian regional health authority. Gastrointest Endosc 2009;69(3 Pt 2):665-71.

2. Sawhney MS, Salfiti N, Nelson DB, Lederle FA, Bond JH. Risk factors for severe delayed postpolypectomy bleeding. Endoscopy 2008;40:115-9.

3. Kim HS, Kim TI, Kim WH, Kim YH, Kim HJ, Yang SK, et al. Risk factors for immediate postpolypectomy bleeding of the colon: a multicenter study. Am J Gastroenterol 2006;101:1333-41. 
4. Kapetanos D, Beltsis A, Chatzimavroudis G, Katsinelos P. Postpolypectomy bleeding: incidence, risk factors, prevention, and management. Surg Laparosc Endosc Percutan Tech 2012;22:102-7.

5. Witt DM, Delate T, McCool KH, Dowd MB, Clark NP, Crowther $\mathrm{MA}$, et al. Incidence and predictors of bleeding or thrombosis after polypectomy in patients receiving and not receiving anticoagulation therapy. J Thromb Haemost 2009;7:1982-9.

6. Garcia DA, Regan S, Henault LE, Upadhyay A, Baker J, Othman $\mathrm{M}$, et al. Risk of thromboembolism with short-term interruption of warfarin therapy. Arch Intern Med 2008;168:63-9.

7. Blacker DJ, Wijdicks EF, McClelland RL. Stroke risk in anticoagulated patients with atrial fibrillation undergoing endoscopy. Neurology 2003;61:964-8.

8. Moon HS, Park SW, Kim DH, Kang SH, Sung JK, Jeong HY. Only the size of resected polyps is an independent risk factor for delayed postpolypectomy hemorrhage: a 10-year single-center casecontrol study. Ann Coloproctol 2014:30;182-5.

9. Watabe H, Yamaji Y, Okamoto M, Kondo S, Ohta M, Ikenoue T, et al. Risk assessment for delayed hemorrhagic complication of colonic polypectomy: polyp-related factors and patient-related factors. Gastrointest Endosc 2006;64:73-8.

10. Lee SH, Chung IK, Kim SJ, Kim JO, Ko BM, Kim WH, et al. Comparison of postpolypectomy bleeding between epinephrine and saline submucosal injection for large colon polyps by conventional polypectomy: a prospective randomized, multicenter study. World J Gastroenterol 2007;13:2973-7.

11. Di Giorgio P, De Luca L, Calcagno G, Rivellini G, Mandato M, De Luca B. Detachable snare versus epinephrine injection in the prevention of postpolypectomy bleeding: a randomized and controlled study. Endoscopy 2004;36:860-3.

12. Paspatis GA, Paraskeva K, Theodoropoulou A, Mathou N, Vardas E, Oustamanolakis $\mathrm{P}$, et al. A prospective, randomized comparison of adrenaline injection in combination with detachable snare versus adrenaline injection alone in the prevention of postpolypectomy bleeding in large colonic polyps. Am J Gastroenterol 2006; 101:2805.

13. Kouklakis G, Mpoumponaris A, Gatopoulou A, Efraimidou E, Manolas K, Lirantzopoulos N. Endoscopic resection of large pedunculated colonic polyps and risk of postpolypectomy bleeding with adrenaline injection versus endoloop and hemoclip: a prospective, randomized study. Surg Endosc 2009;23:2732-7.

14. Ji JS, Lee SW, Kim TH, Cho YS, Kim HK, Lee KM, et al. Comparison of prophylactic clip and endoloop application for the prevention of postpolypectomy bleeding in pedunculated colonic polyps: a prospective, randomized, multicenter study. Endoscopy 2014; 46:598-604. 